\title{
Risk assessment and source identification of perfluoroalkyl acids in surface and ground water: Spatial distribution around a mega-fluorochemical industrial park, China
}

\author{
Zhaoyang Liu ${ }^{\mathrm{a}, \mathrm{b}}$, Yonglong Lu ${ }^{\mathrm{a}, *}$, Tieyu Wang ${ }^{\mathrm{a}}$, Pei Wang ${ }^{\mathrm{a}}$, Qifeng Li ${ }^{\mathrm{a}, \mathrm{b}}$, Andrew C. Johnson ${ }^{\mathrm{c}}$, \\ Suriyanarayanan Sarvajayakesavalu ${ }^{\mathrm{d}}$, Andrew J. Sweetman ${ }^{\mathrm{c}, \mathrm{e}}$ \\ a State Key Laboratory of Urban and Regional Ecology, Research Center for Eco-Environmental Sciences, Chinese Academy of Sciences, Beijing 100085, China \\ b University of Chinese Academy of Sciences, Beijing 100049, China \\ ' Centre for Ecology \& Hydrology, Maclean Building, Crowmarsh Gifford Wallingford, Oxon, OX 10 8BB, UK \\ d SCOPE (Scientific Committee on Problems of the Environment) Beijing Office, P.O. Box 2871,18 Shuangqing Road, Haidian District, Beijing 100085, China \\ e Lancaster Environment Centre, Lancaster University, Lancaster LA1 4YQ, UK
}

\section{A R T I C L E I N F O}

\section{Article history:}

Received 9 January 2016

Received in revised form 4 February 2016

Accepted 14 February 2016

Available online 22 February 2016

\section{Keywords:}

PFAAs

Fluorochemical industrial park

Transport

Attenuation

Risk

\begin{abstract}
A B S T R A C T
Perfluoroalkyl acids (PFAAs) can be released to water bodies during manufacturing and application of PFAA-containing products. In this study, the contamination pattern, attenuation dynamics, sources, pathways, and risk zoning of PFAAs in surface and ground water was examined within a $10 \mathrm{~km}$ radius from a mega-fluorochemical industrial park (FIP). Among 12 detected PFAAs, perfluorooctanoic acid (PFOA) dominated, followed by shorter-chained perfluoroalkyl carboxylic acids (PFCAs). PFAA-containing waste was discharged from the FIP, with levels reaching $1.86 \mathrm{mg} / \mathrm{L}$ in the nearby rivers flowing to the Bohai sea together with up to $273 \mu \mathrm{g} / \mathrm{L}$ in the local groundwater in the catchment. These levels constitute a human health risks for PFOA and other shorter-chained PFCAs within this location. The concentrations of $\sum$ PFAAs in surface water strongly correlated with the local groundwater. The dominant pollution pathways of PFAAs included (i) discharge into surface water then to groundwater through seepage, and (ii) atmospheric deposition from the FIP, followed by infiltration to groundwater. As the distance increased from the source, PFAAs levels in groundwater showed a sharp initial decrease followed by a gentle decline. The contamination signal from the FIP site on PFAAs in groundwater existed within a radius of $4 \mathrm{~km}$, and at least $3 \mathrm{~km}$ from the polluted Dongzhulong River. The major controlling factor in PFAA attenuation processes was likely to be dilution together with dispersion and adsorption to aquifer solids. The relative abundance of PFOA (C8) declined while those of shorter-chained PFCAs (C4-C6) increased during surface water seepage and further dispersion in groundwater.
\end{abstract}

(c) 2016 Elsevier Ltd. All rights reserved.

\section{Introduction}

Perfluoroalkyl acids (PFAAs) have been widely used in manufacturing processes and products, such as surfactants and surface protectors, performance chemicals, lubricants and pesticides, due to their unique properties, including surface activity, heat and acid resistance, and water and oil repellency (Giesy and Kannan, 2001, 2002). However, concerns have been raised due to the environmental persistence, toxicity, long-range transport and bioaccumulation properties of PFAAs (Lescord et al., 2015; Liu et al., 2015; Wang et al., 2015). Continuous release of these substances from various products and applications has made them ubiquitous in environments, such as air (Taniyasu et al., 2013a), water (Wang et al., 2012), sediment (Yeung et al., 2013), wildlife (Persson et al., 2013) and even the human body (Kannan et al., 2004). In addition, water has become the primary reservoir of PFAAs and the major medium for their transportation due to the relatively high polarity

\footnotetext{
* Corresponding author.

E-mail address: yllu@rcees.ac.cn (Y. Lu).
}

and solubility of ionic PFAAs (Prevedouros et al., 2006; Sharma et al., 2015). Because of these physicochemical properties, PFAAs can even be used as useful chemical tracers of global circulation of ocean waters (Yamashita et al., 2008).

PFAAs can be released to the surrounding environment during manufacturing and the application of PFAA-containing products (Wang et al., 2014b). The presence of perfluorooctane sulfonate (PFOS) in the environment is usually associated with discharge from industries such as metal plating, textile treatment and PFOS manufacture, while most perfluorooctanoic acid (PFOA) is derived from PFOA production and fluoropolymer manufacturing and processing (Xie et al., 2013b; Li et al., 2015). Manufacturing facilities are major sources for PFAAs in surface and ground water, the contamination can continue even if the facilities have terminated the production of PFAA-related products (Xiao et al., 2012a). PFAA levels in groundwater affected by a former manufacturing facility from the 1940s to 2002 are still as high as $24 \mu \mathrm{g} / \mathrm{L}$ for PFOA and $1.6 \mu \mathrm{g} / \mathrm{L}$ for PFOS (Xiao et al., 2015). Moreover, PFAAs are also discharged from domestic sewage (Xie et al., 2013a). The 
mobility of long-chained PFAAs is reduced by their sorption to soil and sediment, while the less hydrophobic, short-chained, PFAAs are more likely to undergo long-distance transport in surface water or penetrate to groundwater (Ahrens et al., 2009). The generally slow movement of groundwater makes this environment more of a sink, while contamination of surface water can lead to widespread dissemination (Lin et al., 2015). High concentrations of PFAAs in surface and ground water could pose not only a potential health risk via consumption of drinking water but also a risk to wildlife in aquatic ecosystems (Mak et al., 2009; Giesy et al., 2010). PFAAs are not readily removed by conventional drinking-water treatment processes (Eschauzier et al., 2012; Xiao et al., 2013). Hence, it is very important to identify and control PFAA contamination and prevent it entering drinking water sources.

Although the production of PFAA-related chemicals has been discontinued in Europe and America (UNEP, 2009; USEPA, 2013), it continues to increase in China due to the domestic and international demands. A previous study has shown that the main sources of PFAAs in the South Bohai coastal region were located in the Xiaoqing River basin (Wang et al., 2014a). The major source is a mega-fluorochemical industrial park (FIP), a fluoropolymer production centre with an annual capacity of 50,000 tons of tetrafluoroethylene (TFE), 37,000 tons of polytetrafluoroethylene (PTFE), 10,000 tons of hexafluoropropylene (HFP) and more than 200,000 tons of different types of fluorinated refrigerants (Dongyue Group Limited, 2012). Previous studies demonstrated that fluoropolymer manufacturers can seriously contaminate surface water with PFAAs (Heydebreck et al., 2015; Shi et al., 2015), but less is known about local groundwater contamination by such industrial sites and the relationship with polluted surface water.

The purpose of this paper was to study the environment around the fluoropolymer production facility (FIP) with particular emphasis on (i) groundwater monitoring of PFAAs pollution, (ii) PFAA contamination pattern and attenuation dynamics, (iii) analyzing PFAA sources and pathways, (iv) determining extent of local pollution from the FIP, and (v) conducting a risk analysis for the local surface and ground water with regard to human drinking water safety and ecology.

\section{Materials and methods}

\subsection{Sampling design and collection}

Beneath the FIP in Huantai County, Shandong Province, China, groundwater can be found at an average depth of $12.5 \mathrm{~m}$ from the surface. This is an alluvial sandy aquifer which is unconfined or microconfined with a depth of less than $90 \mathrm{~m}$. The groundwater samples were collected from a series of boreholes which had been installed two years previously. Sampling was done using a submersible pump, with over $100 \mathrm{~L}$ being pumped and discarded before taking the actual sample in 1-L polypropylene bottles. Surface water samples were collected from the Dongzhulong River and Xiaoqing River together with groundwater samples from the Dongzhulong River catchment (Fig. 1). The study area is a major grain-producing zone with large tracts of farmland and scattered villages, while surface and ground water played an important role for human consumption and irrigation. In October 2014, 10 samples of surface water and 37 samples of groundwater were collected. Collected samples were stored in an icebox during transport, all samples were extracted within 1 week after arrival in the lab, and the remainder stored at $-20{ }^{\circ} \mathrm{C}$ for long-term reference. Parameters, including $\mathrm{pH}$, dissolved oxygen, conductance, water temperature and salinity, were determined in situ using a HQd Portable and Benchtop Meter Configurator (HACH Company, USA) (Table S1). Before analysis, all the samples were allowed to stand for $24 \mathrm{~h}$ to settle any sediment and then $400 \mathrm{~mL}$ of supernatant was taken from each

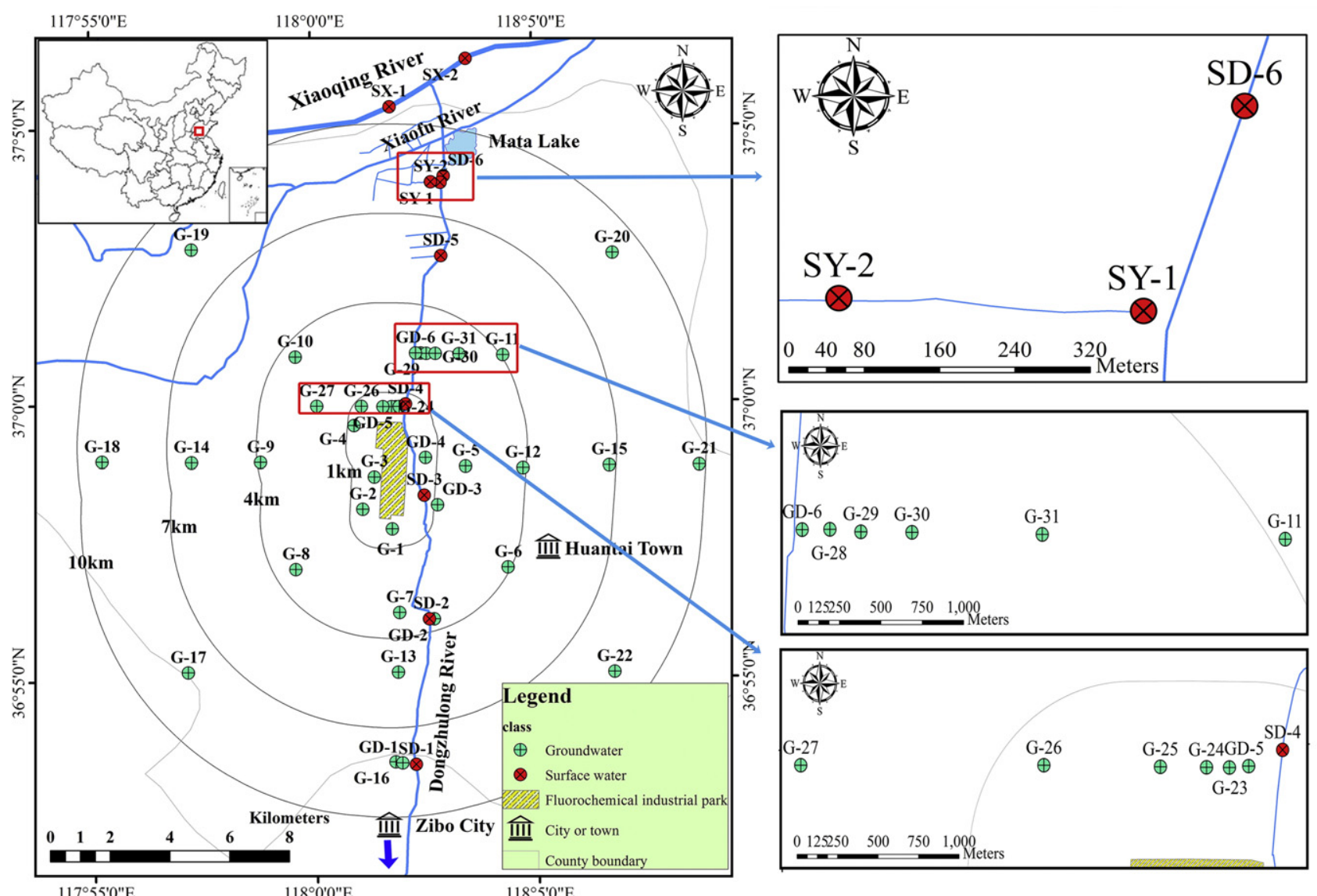

Fig. 1. Map of the sampling locations for surface water and groundwater in Huantai County. 
sample for analysis. Site information, borehole depths and ambient description were also shown in Table S2.

\subsection{Standards and reagents}

All samples were analyzed for 12 PFAAs, including perfluorobutanoic acid (PFBA), perfluoropentanoic acid (PFPeA), perfluorohexanoic acid (PFHxA), perfluoroheptanoic acid (PFHpA), PFOA, perfluorononanoic acid (PFNA), perfluorodecanoic acid (PFDA), perfluoroundecanoic acid (PFUnDA), perfluorododecanoic acid (PFDoA), perfluorobutane sulfonate (PFBS), perfluorohexane sulfonate (PFHxS), PFOS. The detailed descriptions on standards and reagents are available in Supplementary Information.

\subsection{Extraction and cleanup}

Water samples were extracted by OASIS WAX-SPE using a previously described method (Taniyasu et al., 2005) with minor modification and optimization. Briefly, the Oasis WAX cartridges (6 cc, $150 \mathrm{mg}, 30 \mathrm{~mm}$, Waters, Milford, MA, USA) was sequentially preconditioned with $4 \mathrm{~mL}$ of $0.1 \% \mathrm{NH}_{4} \mathrm{OH}$ in methanol, $4 \mathrm{~mL}$ methanol and $4 \mathrm{~mL}$ Milli-Q water. The 400-mL aliquot of water sample was spiked with $5 \mathrm{ng}$ internal standard $\left({ }^{13} \mathrm{C}_{4}\right.$ PFBA, ${ }^{13} \mathrm{C}_{4}$ PFHxA, ${ }^{13} \mathrm{C}_{4}$ PFOA, ${ }^{13} \mathrm{C}_{4}$ PFNA, ${ }^{13} \mathrm{C}_{4}$ PFDA, ${ }^{13} \mathrm{C}_{4}$ PFUdA, ${ }^{13} \mathrm{C}_{2}$ PFDoA, ${ }^{18} \mathrm{O}_{2}$ PFHxS and ${ }^{13} \mathrm{C}_{4}$ PFOS), mixed thoroughly and then loaded into the cartridges. The cartridges were washed with $4 \mathrm{~mL}$ of $25 \mathrm{mM}$ ammonium acetate ( $\mathrm{pH} 4$ ), air-dried overnight, and successively eluted with $4 \mathrm{~mL}$ of methanol and $4 \mathrm{~mL}$ of $0.1 \% \mathrm{NH}_{4} \mathrm{OH}$ in methanol. The eluents were collected and concentrated to $1 \mathrm{~mL}$ under a gentle stream of high-purity nitrogen (99.999\%, Haidian District, Beijing, China), then filtered through a nylon filter $(13 \mathrm{~mm}, 0.2 \mathrm{~mm}$, Chromspec, Ontario, Canada) into a $1.5-\mathrm{mL}$ PP snap top auto-sampler via with polyethylene (PE) septa.

\subsection{Instrumental analysis and quantitation}

Individual PFAA were separated and quantified using Agilent 1290 Infinity HPLC System equipped with an Agilent 6460 Triple Quadrupole MS/MS System (Agilent Technologies, Palo Alto, CA, USA) in the negative electrospray ionization (ESI) mode. The detailed descriptions on instrumental analysis were available in Supplementary Information and Table S3.

\subsection{Quality assurance and quality control (QA/QC)}

During sampling in the field, in order to avoid cross contamination, the outside of bottles was washed with Milli-Q water after the samples were taken, wiped with clean towel paper and then kept in three-layers of sealed polyethylene bags. Field blanks, transport blanks, procedure blanks and solvent blanks were conducted with every sample set to examine if any external contamination occurred during the sampling/extracting and analytical. The internal standard calibration curve consisting of a concentration gradient $(0.01,0.05,0.1,0.5,1$, $5,10,50$, and $100 \mathrm{ng} / \mathrm{mL}$ ) of native standards, spiked with $5 \mathrm{ng}$ internal standard was prepared for quantification of individual PFAA with coefficients $\left(\mathrm{r}^{2}\right)$ for all target analytes exceeding 0.99 . The limit of detection (LOD) and limit of quantification (LOQ) were defined as the peak of analyte that needed to yield a signal-to-noise $(\mathrm{S} / \mathrm{N})$ ratio of 3:1 and 10:1, respectively. When PFAA concentration was detected over $100 \mathrm{ng} / \mathrm{mL}$ in any extract, the extract would be diluted to fit the range of the calibration series and measured again. Matrixes spiked with a standard solution were analyzed to determine the recovery of each target PFAA and matrix spike recoveries (MSRs) ranged from $79.0 \%$ to $109 \%$. The detailed QA/QC information was given in Table S4.

\subsection{Statistical and spatial analyses}

Statistical analysis was performed using SPSS Statistics V22.0 (SPSS Inc. Quarry Bay, HK). During the analysis, concentrations less than the LOQ were set to one-half of the LOQ, and those less than the LOD were assigned to values of LOD $/ \sqrt{2}$ (Bao et al., 2011). Spatial distributions of PFAAs were analyzed using the Arcmap module in ArcGIS V10.2 software (ESRI, Redland, CA, USA).

\subsection{Data representation}

Because of the large variation in concentrations over orders of magnitude, the accuracy of all data has been presented using three significant figures. Units for concentrations in water were $\mathrm{ng} / \mathrm{L}, \mu \mathrm{g} / \mathrm{L}$ or $\mathrm{mg} / \mathrm{L}$, respectively.

\section{Results and discussion}

\subsection{Occurrence and source identification of PFAAs in surface and ground water}

Each of the 12 PFAAs was detected in this study (Table S4). The concentrations of sum PFAAs ( $\sum$ PFAAs) ranged from $55.7 \mathrm{ng} / \mathrm{L}$ to $1.86 \mathrm{mg} / \mathrm{L}$ in surface water samples, and from $1.68 \mathrm{ng} / \mathrm{L}$ to $273 \mu \mathrm{g} / \mathrm{L}$ in groundwater samples (Table S5). PFOA was the dominant component with average contribution of $81.6 \%$ to $\sum$ PFAAs in surface water and $65.3 \%$ to $\sum$ PFAAs in groundwater, followed by C4-C7 shorter-chained perfluoroalkyl carboxylic acids (PFCAs) including PFBA, PFPeA, PFHxA and PFHpA. To the best of our knowledge, the PFOA concentration in surface water $(1.71 \mathrm{mg} / \mathrm{L})$ reported in this study is the highest ever found (reviewed in Table S6). Previous studies near this location found slightly lower levels of PFOA $(0.37 \mathrm{mg} / \mathrm{L}-0.97 \mathrm{mg} / \mathrm{L}$ ) (Shi et al., 2015; Wang et al., 2016), which may indicate an increasing emission of PFAAs to the studied river. Except for $6.57 \mathrm{mg} / \mathrm{L}$ caused by AFFF infiltration in Tyndall Air Force Base (USA) (Moody and Field, 1999), the concentration of PFOA in groundwater $(240 \mu \mathrm{g} / \mathrm{L})$ in our study also represents the highest found so far (reviewed in Table S7). Longerchained PFCAs (C9-C12) and perfluoroalkane sulfonic acids (PFSAs) including PFBS, PFHxS and PFOS were only observed in low concentrations or below the MDL, which were likely due to limited production and application of these components in this region (Xie et al., 2013b).

Principal component analysis (PCA) and correlation analysis on the 12 PFAAs in surface and ground water showed that the concentrations of PFCAs, including PFBA, PFPeA, PFHxA, PFHpA, PFOA, PFNA, PFDA and PFDoDA, were strongly associated, indicating that these compounds came from similar sources (Fig. 2; Fig. S1, Tables S8-S11). The FIP in the study area included not only PFOA production but also fluoropolymer manufacturing and processing, and these two industries were estimated to contribute $83.7 \%$ and 8.3\% of PFOA in the environment, respectively (Li et al., 2015). Shorter- and longer-chained PFAAs can be emitted as impurities or by-products during PFOA production. Additionally, degradation of PFAAs and precursors, through photolysis and biodegradation can also be an important source (Dinglasan et al., 2004; Taniyasu et al., $2013 b)$. The increase of most PFAAs, especially PFOA, nearby or immediately downstream of the FIP indicated it was the principal source of PFAAs, not only in surface water but also in groundwater. However, other sources of PFAAs in surface and ground water were inferred to exist based on the PCA results. Domestic emission, wastewater treatment plant (WWTP) effluent and other industrial emissions are known to be potential sources of PFAAs (Bossi et al., 2008; Wang et al., 2014c). The concentrations of $\sum$ PFAAs increased to various degrees after receiving emissions from these sources in the study. 

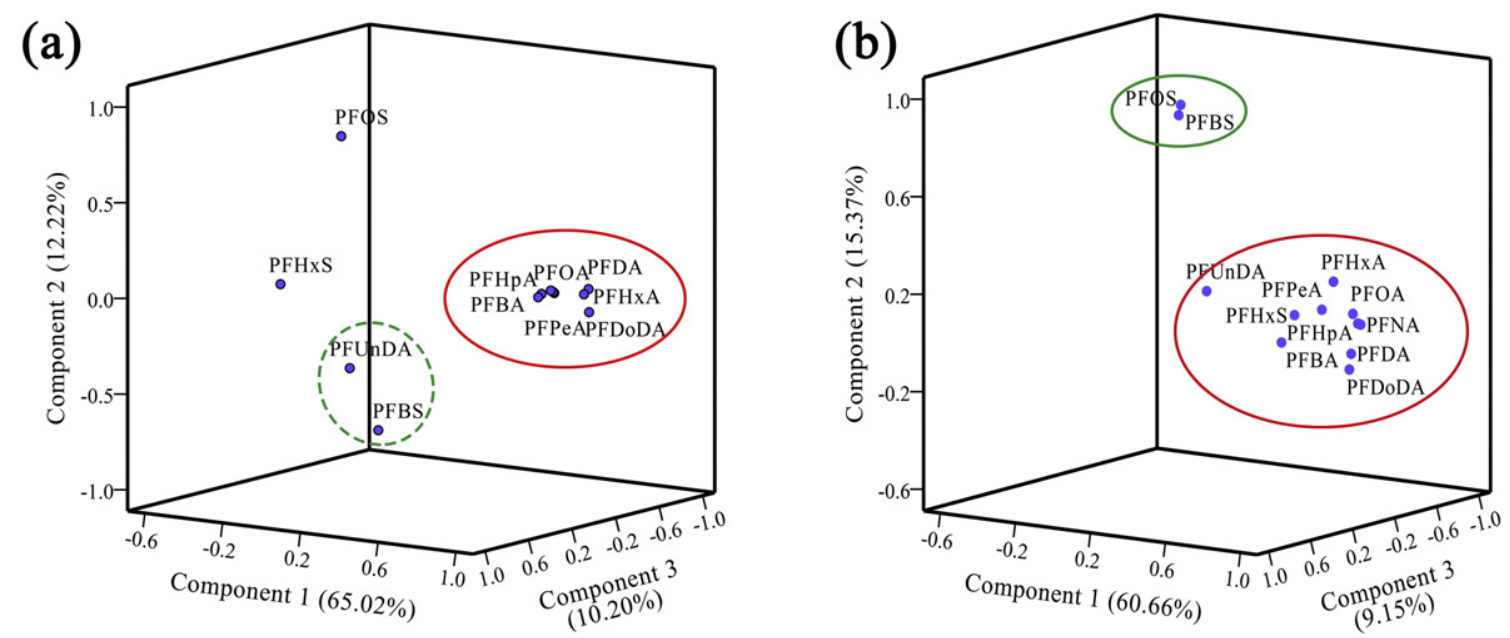

Fig. 2. PCA results using concentrations of 12 PFAAs in surface water (a) and groundwater (b).

\subsection{Emission and lateral pathway of PFAAs in surface water}

3.2.1. Transport and exchange of PFAAs between surface water and groundwater

The Dongzhulong River first flows through Zibo City and receives domestic wastewater, before receiving industrial discharge including waste from the FIP and then entering the Xiaoqing River. Upstream of the FIP, PFOA dominated with concentrations of $1.2 \mathrm{ng} / \mathrm{L}-401 \mathrm{ng} / \mathrm{L}$ and a contribution of $29.1 \%-81.8 \%$ to $\sum$ PFAAs (Fig. 3). PFAAs could be detected at site SD-1 (55.7 ng/L), which suggested domestic emissions or urban stormwater runoff from the Zibo City was occurring (Xiao et al., 2012a; Xiao et al., 2012b). The concentration of $\sum$ PFAAs at site GD-1 (groundwater adjacent to SD-1) was $2.09 \mathrm{ng} / \mathrm{L}$ was much lower than that in nearby surface water. The concentration of $\sum$ PFAAs at site SD-2 and GD-2 increased to $73.8 \mathrm{ng} / \mathrm{L}$ and $37.8 \mathrm{ng} / \mathrm{L}$ respectively, due to effluents from a WWTP. Closer to the FIP, the concentrations of $\sum$ PFAAs increased to $168 \mathrm{ng} / \mathrm{L}$ in surface water at SD-3 and $410 \mathrm{ng} / \mathrm{L}$ and $490 \mathrm{ng} / \mathrm{L}$ in groundwater at GD-3 and GD-4, respectively. Although

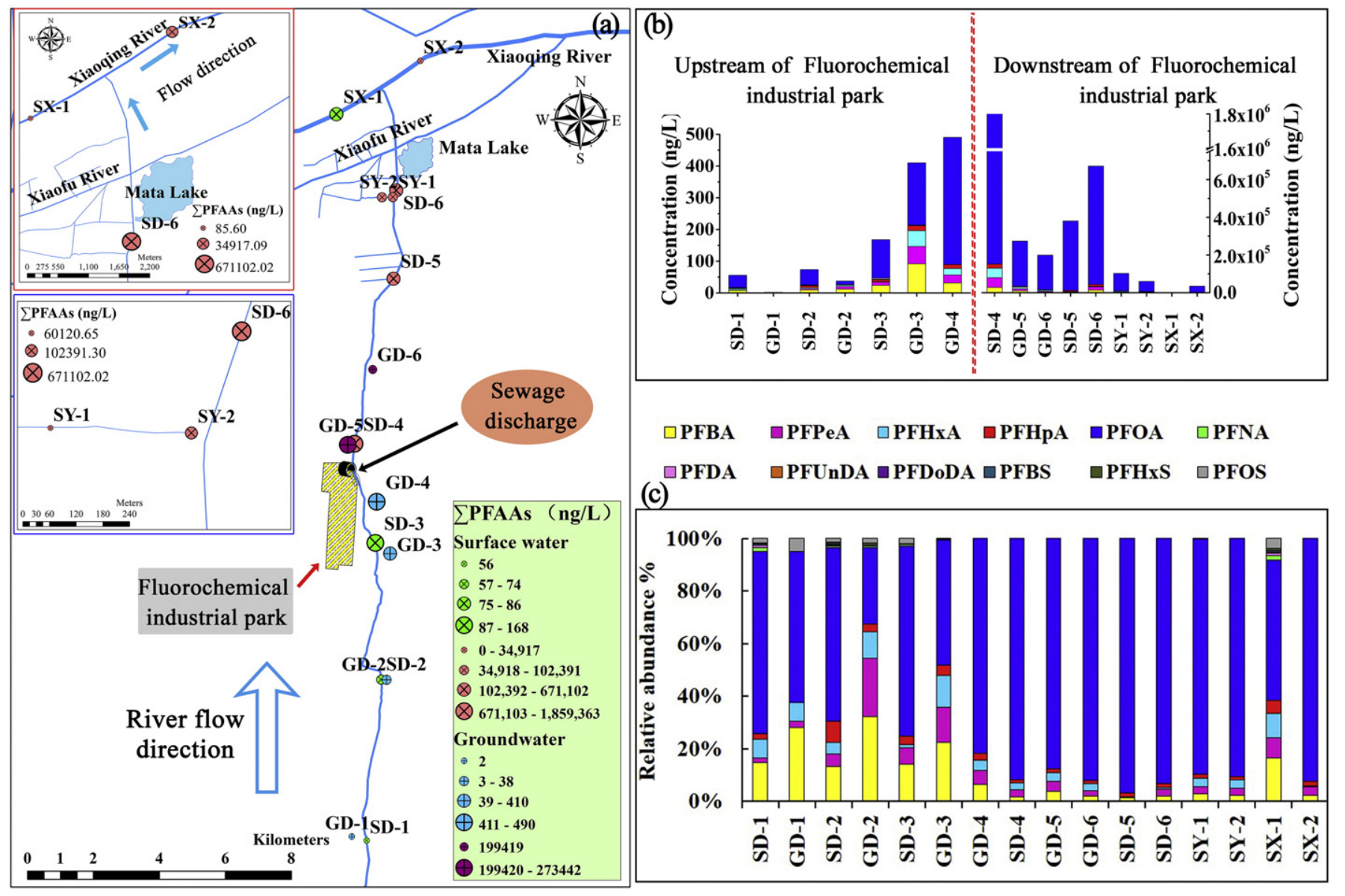

Fig. 3. Spatial distribution of PFAAs in surface and ground water adjacent to the Dongzhulong River. 
located before the waste discharge point from the FIP, these sites might be influenced through diffusion and dispersion of PFAAs from general industrial activity in the area.

Downstream of the FIP, the concentrations of $\sum$ PFAAs in surface water of the Dongzhulong River and the Xiaoqing River and groundwater increased to extremely high levels and the relative abundance of individual PFAA also changed (Fig. 3). At SD-4, which was located immediately downstream of the effluent from the FIP (500 m away from the wastewater outfall), the concentration of $\sum$ PFAAs in surface water at SD-4 soared to $1.86 \mathrm{mg} / \mathrm{L}$, and that in groundwater at GD-5 was also high at $273 \mu \mathrm{g} / \mathrm{L}$. PFOA at SD-4, with a concentration of $1.71 \mathrm{mg} / \mathrm{L}$, represented $91.8 \%$ of $\sum$ PFAAs, followed by PFPeA (51.4 $\mu \mathrm{g} / \mathrm{L}, 2.77 \%)$, PFHXA (50.3 $\mu \mathrm{g} / \mathrm{L}, 2.71 \%)$, PFBA (28.3 $\mu \mathrm{g} / \mathrm{L}, 1.52 \%)$ and PFHpA (21.3 $\mu \mathrm{g} / \mathrm{L}, 1.15 \%)$. The concentration of PFOA at GD-5 also increased up to $240 \mu \mathrm{g} / \mathrm{L}$, which contributed $87.6 \%$ of $\sum$ PFAAs, followed by PFPeA (10.6 $\mu \mathrm{g} / \mathrm{L}, 3.87 \%)$, PFBA (10.5 $\mu \mathrm{g} / \mathrm{L}, 3.85 \%)$, PFHxA (8.88 $\mu \mathrm{g} / \mathrm{L}$, $3.25 \%$ ), and $\mathrm{PFHpA}(3.73 \mu \mathrm{g} / \mathrm{L}, 1.37 \%)$. Although total relative abundance of the longer-chained PFCAs (C9-C12) in these two sites were less than $0.04 \%$, they also showed notable concentrations such as PFNA (SD-4: 430 ng/L, GD-5: 33.5 ng/L), PFDA (SD-4: 181 ng/L, GD-5: 18.7 ng/L) and PFDoDA (SD-4: $83.6 \mathrm{ng} / \mathrm{L}, \mathrm{GD}-5: 17.1 \mathrm{ng} / \mathrm{L}$ ). With increasing distance from the FIP, the concentrations of $\sum$ PFAAs in surface water (SD-5: $380 \mu \mathrm{g} / \mathrm{L}, \mathrm{SD}-6: 671 \mu \mathrm{g} / \mathrm{L}$ ) as well as groundwater (GD-6: $199 \mu \mathrm{g} / \mathrm{L}$ ) showed a downward trend, while the relative abundance of individual PFAA had no obvious change. Seepage to groundwater can be an important source for subsequent contamination or recontamination of rivers (Lin et al., 2015). The proportion of surface water seepage in the Northern Plain of China is estimated to be about 12\% (MWR, 2011, 2013, 2014). Similar source and positive correlation of PFAA concentrations in surface and ground water indicated that most PFAAs in groundwater may come from seepage of contaminated surface water, and then travel through diffusion, dispersion and advection (Xiao et al., 2015).

After the confluence with the Dongzhulong River, the concentration of $\sum$ PFAAs in the Xiaoqing River (an important source of domestic water and agricultural water) increased from $85.6 \mathrm{ng} / \mathrm{L}$ at site SX-1 to $34.9 \mu \mathrm{g} / \mathrm{L}$ at site SX-2. Previous studies have shown that the concentrations of PFAAs in the Xiaoqing River can reach $5.07 \mu \mathrm{g} / \mathrm{L}$ at a distance of $30 \mathrm{~km}$ from the confluence with the contaminated Dongzhulong River, and $3 \mu \mathrm{g} / \mathrm{L}$ at the estuary $92 \mathrm{~km}$ away from the FIP (Wang et al., 2014a). Most farmlands in the northern part of the study area are irrigated by surface water abstraction. To avoid exchange and dispersion of polluted water, irrigation canals were isolated from the Dongzhulong River, but they use the water from the Yellow River itself for irrigation and aquaculture. However, the concentration of PFAAs in diverted Yellow River water at site SY-2 which is $20 \mathrm{~m}$ away from the Dongzhulong River was up to $102 \mu \mathrm{g} / \mathrm{L}$, and it was still $60.1 \mu \mathrm{g} / \mathrm{L}$ at the site SY-1 $350 \mathrm{~m}$ away from the river. The pollution pathway might be through water exchange between diverted Yellow River water and contaminated shallow groundwater.

\subsubsection{Attenuation dynamics of PFAAs levels in aquifer}

Along the lateral direction from the Dongzhulong River ( $\sum$ PFAAs: $1.86 \mathrm{mg} / \mathrm{L}$, max) which received effluents from the FIP, the concentration of $\sum$ PFAAs in groundwater decreased with an exponential trend, showing a sharp initial decrease followed by a more gentle decline (Fig. 4). Moving west from the FIP (transverse A) (Fig. 4a), the concentration of $\sum$ PFAAs in groundwater sharply decreased by 99.1\% (from $273 \mu \mathrm{g} / \mathrm{L}$ to $2.39 \mu \mathrm{g} / \mathrm{L}$ ) within a distance of $200 \mathrm{~m}-750 \mathrm{~m}$, and then declined by $0.73 \%$ to $348.3 \mathrm{ng} / \mathrm{L}$ within the distance of $700 \mathrm{~m}-1.5 \mathrm{~km}$. Once the distance had increased to $3 \mathrm{~km}$ from the polluted river, the concentration of $\sum$ PFAAs was $27.0 \mathrm{ng} / \mathrm{L}$. To the East of the FIP (transverse B) (Fig. 4b), the concentration of $\sum$ PFAAs in groundwater rapidly decreased by $99.2 \%$ (from $199 \mu \mathrm{g} / \mathrm{L}$ to $1.67 \mu \mathrm{g} / \mathrm{L}$ ) within a distance of $50 \mathrm{~m}-700 \mathrm{~m}$, and then fell by $0.73 \%$ to $221 \mathrm{ng} / \mathrm{L}$. As the distance increased to the quantity and concentration fell to $0.02 \%$ and $34.8 \mathrm{ng} / \mathrm{L}$ from $1.5 \mathrm{~km}-3 \mathrm{~km}$. The concentrations of $\sum$ PFAAs at the distance of $3 \mathrm{~km}$ in sample groups (a) and (b) were both an order of magnitude higher than most sites further from the polluted Dongzhulong river (Fig. 5a and b). The contamination signal of PFAAs in groundwater existed within a lateral distance of at least $3 \mathrm{~km}$ from heavily polluted Dongzhulong River. Since most of PFAAs are resistant to chemical decomposition and biochemical attenuation, adsorption to aquifer solids and the dilution caused by dispersion would be major controlling factors in PFAA attenuation processes.

\subsubsection{Composition changes during transportation in surface and ground} water

The relative abundance of PFOA (C8) decreased in the process of surface water seepage and further dispersion in groundwater relative to the shorter-chained PFCAs (C4-C6). During seepage of PFAAs from the Dongzhulong River to the groundwater immediately below, the average relative abundance of PFBA, PFPeA and PFHxA increased by $8.04 \%, 5.05 \%$, and $3.92 \%$ respectively while percentage of PFHpA and PFOA decreased by $0.96 \%$ and $15.6 \%$ (Fig. 3c). A similar pattern was observed when groundwater samples were analyzed with increasing distances to the west (Transect A) and north east (transect B) (Fig. 4d; Fig. S2). Thus, the relative abundance of PFBA (C4) showed the largest increase with distance from the contamination source, followed by PFPeA (C5) and PFHxA (C6). The relative abundance of PFHpA (C7) varied little, while relative abundance of PFOA (C8) decreased significantly in the process of surface water seepage and further dispersion in the aquifer. This observation supports the belief that the longer-chained PFAAs are more susceptible to sorption or attenuation (Higgins and Luthy, 2006). Thus, the shorter-chained PFAAs, with a higher aqueous solubility and a lower adsorption affinity, increase in proportion to the longer-chained varieties due to their greater persistence and mobility in the environment (Ferrey et al., 2009; Ahrens et al., 2010).

\subsection{Dispersion and transport of PFAAs in groundwater from the FIP}

The study area encompassed a range of industrial activities including: A, fluorochemical industries; B, petrochemical, fine chemicals and paper industries; $C$, petrochemical, metallurgical machinery and agricultural processing; D, tourism and village group (Fig. 5).

The signal of groundwater PFAA contamination from the FIP was strong within $1 \mathrm{~km}$ of the complex but was still elevated out to $4 \mathrm{~km}$ distance (Fig. 5b). The concentrations of $\sum$ PFAAs at site G-1 (18.1 $\mu \mathrm{g} / \mathrm{L}), \mathrm{G}-2(1.70 \mu \mathrm{g} / \mathrm{L}), \mathrm{G}-3(147 \mu \mathrm{g} / \mathrm{L})$ and G-4 $(20.7 \mu \mathrm{g} / \mathrm{L})$ south and west from the FIP were much higher than those on the east side at sites GD-3 (410 ng/L) and GD-4 (490 ng/L). Perhaps the Dongzhulong River, which is east of the site, is intercepting much of the PFAAs on this side (Fig. 5a). An isolated hotspot outside the grounds of the FIP was detected at the south eastern side at site G-6 (406 ng/L). This G-6 site was near apartments used by staff who work at the FIP (Fig. 5a). Location G-7 was located near some fine chemical plants, which may also be major users of PFAAs leading to $58.6 \mathrm{ng} / \mathrm{L} \sum$ PFAAs found here (Fig. 5a). Compared with sites within the distance of 4-7 km, the concentration and proportion of PFOA were slightly higher within the distance of 7-10 km, which was probably due to small discharge of PFAAs from the industries and villages in areas B, C and D (Fig. 5a, c). Overall the groundwater pollution signal at the FIP here was larger than that of a PFAA manufacturing facility $(<2 \mathrm{~km})$ in Wuhan, China, which might be due to the sheer scale of this facility (Wang et al., 2010).

An interesting observation was that the total proportion of longerchained PFCAs (C9-C12), which are among the most hydrophobic of PFAAs, increased with distance from the FIP up to a distance of $7 \mathrm{~km}$ (from $0.13 \%$ within $<1 \mathrm{~km}$ to $18.5 \%$ within the distance of $4-7 \mathrm{~km}$ ), which implied a different contamination route to groundwater for these compounds. Previous studies have assessed the fate and transport pathways of longer-chained PFAAs emitted from direct sources (i.e., manufacturing and use) (Armitage et al., 2009), and have suggested 
(a)

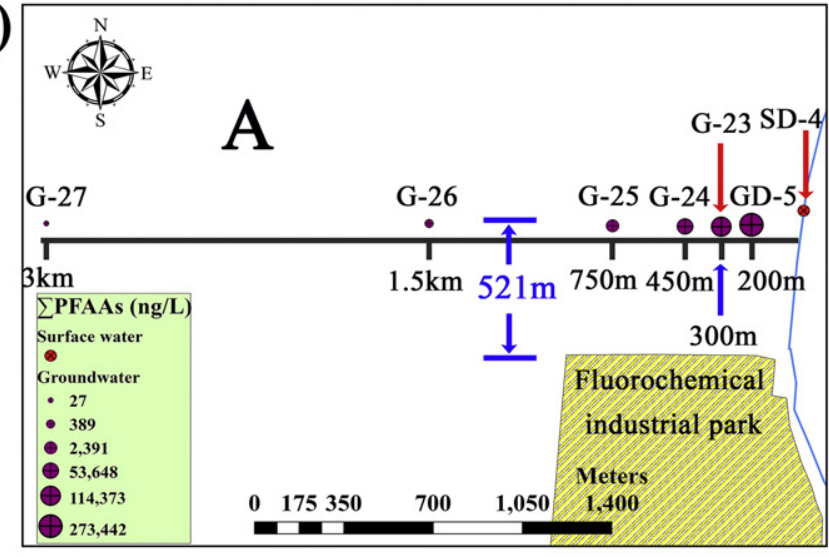

(b)

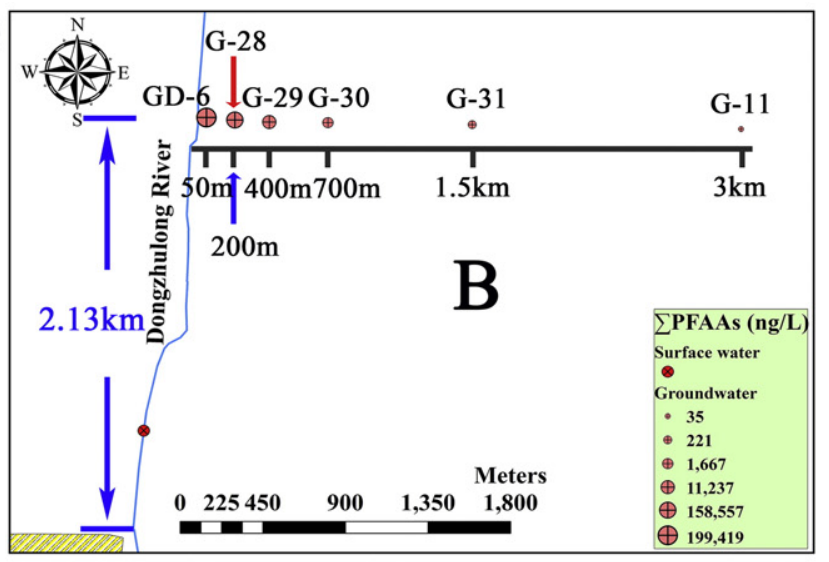

(c)

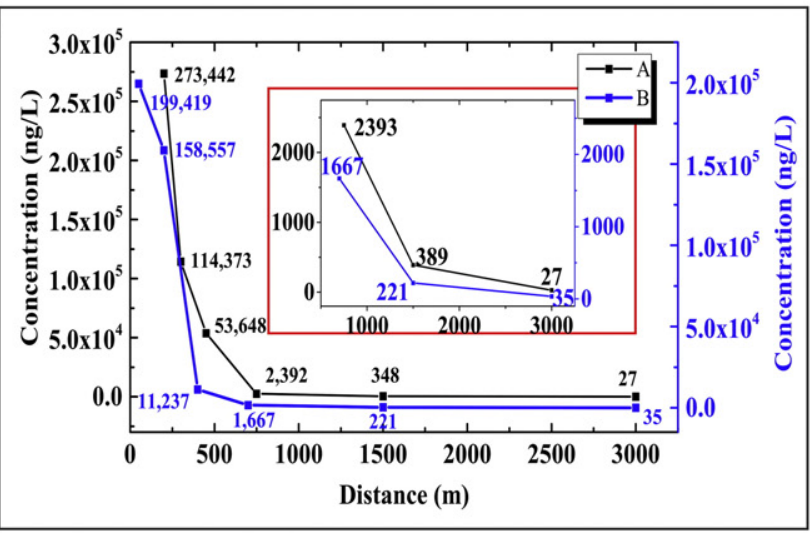

(d)

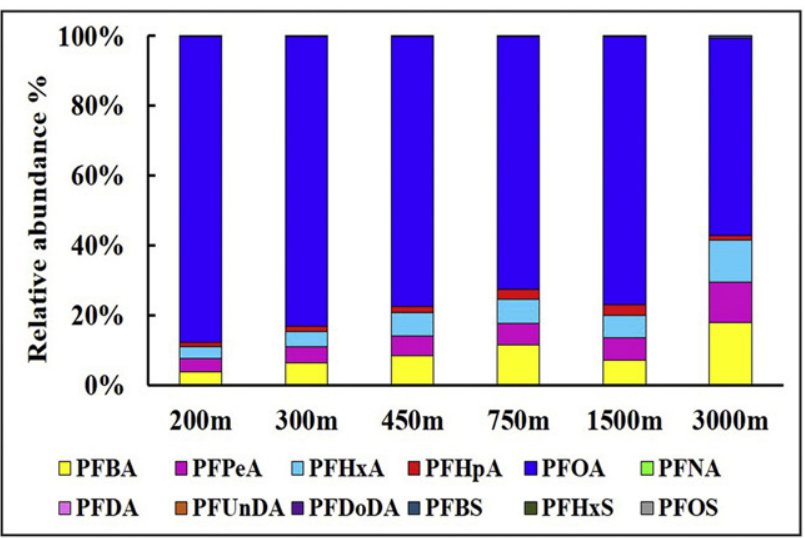

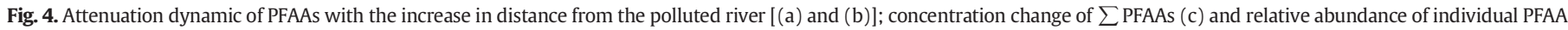
(d) with the increase in distance.

that atmospheric transport makes an important contribution to transport potential for longer-chained PFAAs. PFAAs can be released into the air during PFAA and fluoropolymer production (Wang et al., 2013; Li et al., 2015). Therefore, it is suggested that air emission from the FIP followed by deposition was a major source of these longer-chained PFCAs to the more distant groundwater (Kwok et al., 2010).

\subsection{Risks of PFAAs in surface and ground water to human health and ecology}

As groundwater is an important option for drinking water, the potential risks analysis to human health from the local surface and ground water was made. While PFOS concentrations were much lower than reported health and ecological risk thresholds, there was more concern with PFOA. A range of current available standards for PFOA in drinking water have been proposed (Table 1 ) with some concerns beginning at $40 \mathrm{ng} / \mathrm{L}$. These two US standards were used to divide different levels of potential risk areas: the areas where the concentrations of PFOA were comparable to or higher than $400 \mathrm{ng} / \mathrm{L}$ were defined as high risk areas; the areas where the concentrations of PFOA were between $40 \mathrm{ng} / \mathrm{L}$ and $400 \mathrm{ng} / \mathrm{L}$ were defined as medium risk areas; and the areas where the concentrations of PFOA were lower than $40 \mathrm{ng} / \mathrm{L}$ were defined as low risk areas.

By these standards, high risk areas in groundwater were within a radius of $1 \mathrm{~km}$ from the FIP and within a distance of $1.5 \mathrm{~km}$ from the polluted Dongzhulong River (Fig. 6). Within this high risk zone some values even exceeded the UK Notification of Event $45 \mu \mathrm{g} / \mathrm{L}$ level. For shorterchained PFCAs (C4-C6), the concentrations in high risk areas were also mostly higher than their Health-Related Indication Values (HRIV), Germany (Table S12) (Wilhelm et al., 2010). Due to this health risk, untreated groundwater in these areas should not been used as drinking water. The medium risk areas extended to $4 \mathrm{~km}$ from the FIP and $3 \mathrm{~km}$ from the polluted river (Fig. 6). Groundwater in these areas was also not suggested to be used as drinking water directly. Areas with greater distance from the FIP and polluted river had a low risk, where most concentrations of PFOA detected were comparable to those in tap water of China and some other countries (Mak et al., 2009; Jin et al., 2009).

Surface water and groundwater are dominant sources of irrigation water for large tracts of farmland and vegetable plots. Heavily polluted surface and ground water used for irrigation might pose risks due to PFAAs in soils and subsequent accumulation into crops and vegetables and eventual accumulation in humans (Blaine et al., 2014; Wen et al., 2014). Local surface water and groundwater are believed to be also used for poultry farming and aquaculture. Poultry and aquatic products were inclined to accumulate longer-chained PFAAs with higher toxicity and accumulation (Gewurtz et al., 2013; Gebbink et al., 2015) and intake of these products may also lead to potential human health risks (Domingo, 2012). Extremely high concentrations of PFOA in the heavily polluted Dongzhulong River were comparable to criteria continuous concentration (CCC) of $2.9 \mathrm{mg} / \mathrm{L}$, and even triple of the predicted noneffect concentration (PNEC) of $570 \mu \mathrm{g} / \mathrm{L}$ in China, indicating a potential aquatic ecological risk (Table S13)(Giesy et al., 2010; Cao et al., 2013).

\section{Conclusions and perspectives}

Overall, the results of this study indicated that:

- High concentrations of $\sum$ PFAAs were observed in the Dongzhulong River, downstream of the FIP effluent, including $1.86 \mathrm{mg} / \mathrm{L}$ in surface water and $273 \mu \mathrm{g} / \mathrm{L}$ in groundwater, respectively. A strong correlation was observed between the concentrations in surface water and that in the groundwater below. 

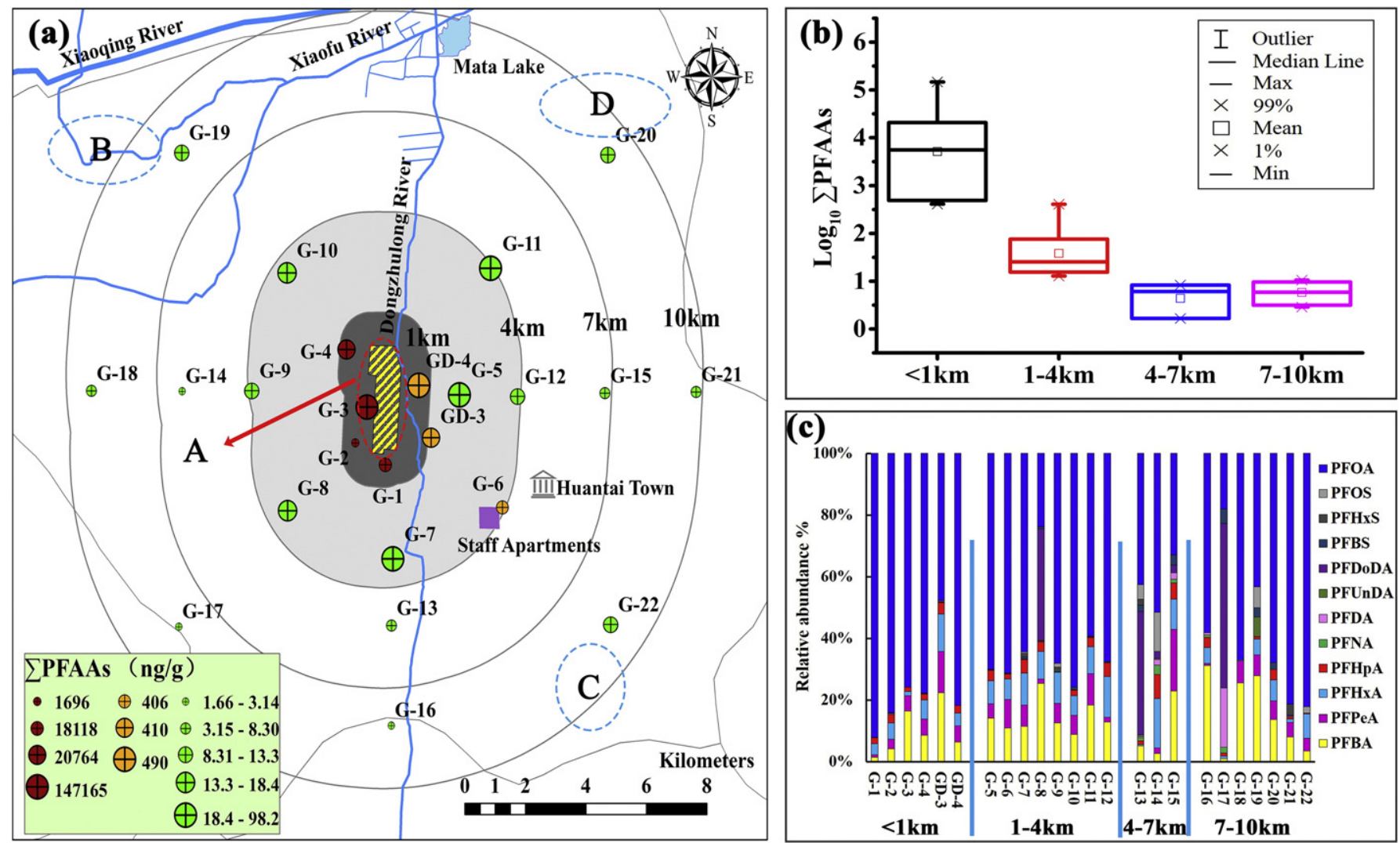

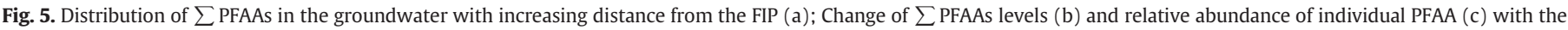
increase in distance.

- Emission from the FIP was the principal source of PFAAs in surface water and groundwater. It was considered that contamination occurred primarily from discharge through wastewater into surface water then seepage to groundwater. In addition, air emission from the FIP, deposition then infiltration was also playing a role. Surface water may also be polluted by contaminated groundwater through water exchange.

- PFOA was the predominant PFAA with average relative abundance of $81.6 \%$ in surface water and $65.3 \%$ in groundwater, followed by shorter-chained PFCAs such as PFBA, PFPeA, PFHxA, PFHPA. The relative abundance of PFOA (C8) declined while percentage of shorter-chained PFCAs (C4-C6) increased with increasing distances from the contamination source.

- The signal of contamination from the FIP on PFAAs in groundwater existed within a radius of $4 \mathrm{~km}$, and within a lateral distance of at least $3 \mathrm{~km}$ from the polluted Dongzhulong River. Adsorption to aquifer solids and dilution were considered the major controlling factors in PFAA attenuation processes.

- Concentrations of PFOA and other shorter-chained PFCAs in the local contaminated river and groundwater within a radius of $1 \mathrm{~km}$ from the FIP and within a distance of $1.5 \mathrm{~km}$ along the river exceed current available standards for drinking water. Use of the contaminated water for livestock and vegetables may indirectly lead to human health concerns.
- As industry shifts toward the manufacture of fluorinated alternatives including PFOA and shorter-chained PFAAs, so continued vigilance on the health and ecological risks will be needed. In particular, more consideration is required for the potential hazards of aquatic products, livestock and poultry, and crops from these chemicals.

\subsection{Management options}

For fluoropolymer manufacturers, non-fluorinated alternatives that are neither persistent nor toxic should be developed while PFAA removal facilities, for example granular activated carbon system, could be considered for wastewater treatment system (Rumsby et al., 2009; Blum et al., 2015). Management of staff uniforms and shuttle buses should be strengthened, and staff suits, trucks and shuttle buses should be regularly cleaned to avoid PFAA pollution during transport.

For government, legislation and policy should be strictly enforced to extend producer responsibility and strictly control PFAAs emissions. Regular contaminant monitoring should include the PFAAs to identify and control pollution. Advanced tap water systems and supporting purification devices are also vital to ensure the safety of drinking water.

Table 1

Current available standards for PFOA in drinking water.

\begin{tabular}{|c|c|c|c|}
\hline Reference & Organisation & Requirement & Concentration \\
\hline Post et al. (2011) & Preliminary Health-Based Guidance (PHBG) in New Jersey, USA & Drinking water quality standard & $40 \mathrm{ng} / \mathrm{L}$ \\
\hline USEPA (2014) & Provisional Health Advisory (PHA) by the USEPA & Advised drinking water threshold & $400 \mathrm{ng} / \mathrm{L}$ \\
\hline DWI (2009) & Notification of Event by drinking water inspectorate, UK & To be reported as dangerous pollution & $45 \mu \mathrm{g} / \mathrm{L}$ \\
\hline
\end{tabular}

Note: Detailed information about risk analysis was introduced in Supplementary Information. 


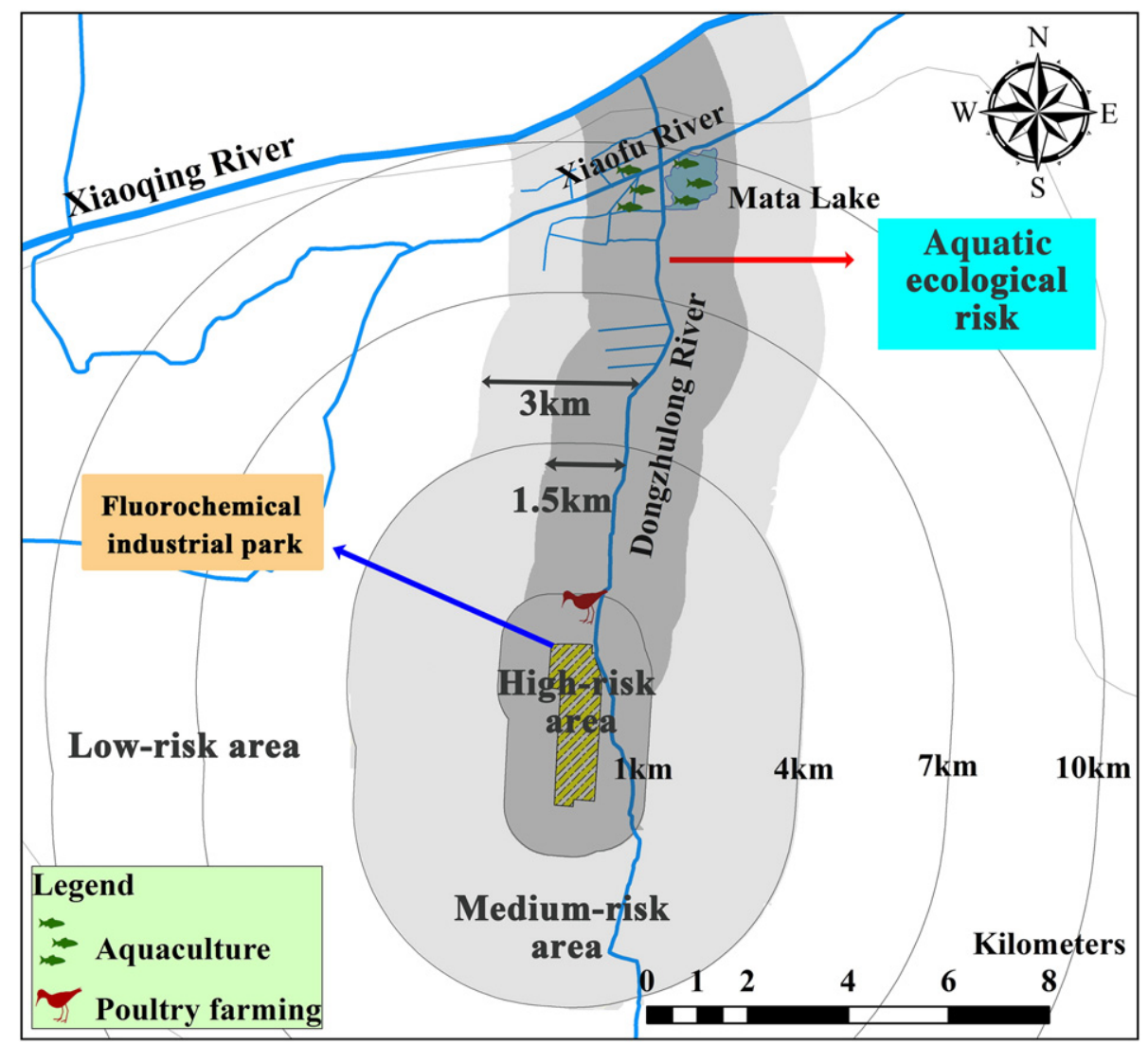

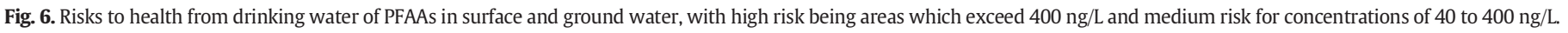

\section{Acknowledgement}

This study was supported by the National Natural Science Foundation of China under Grant No. 414201040045 and No. 41371488 , the International Scientific Cooperation Program with Grant No. 2012DFA91150, and the Key Project of the Chinese Academy of Sciences under Grant No. KZZD-EW-TZ-12. A.C. Johnson is grateful for CEH National Capability funding provided by NERC.

\section{Appendix A. Supplementary data}

Supplementary data to this article can be found online at http://dx. doi.org/10.1016/j.envint.2016.02.020.

\section{References}

Ahrens, L., Yamashita, N., Yeung, L.W., Taniyasu, S., Horii, Y., Lam, P.K., Ebinghaus, R., 2009. Partitioning behavior of per-and polyfluoroalkyl compounds between pore water and sediment in two sediment cores from Tokyo Bay, Japan. Environ. Sci. Technol. 43 (18), 6969-6975.

Ahrens, L., Taniyasu, S., Yeung, L.W., Yamashita, N., Lam, P.K., Ebinghaus, R., 2010. Distribution of polyfluoroalkyl compounds in water, suspended particulate matter and sediment from Tokyo Bay, Japan. Chemosphere 79 (3), 266-272.

Armitage, J.M., MacLeod, M., Cousins, I.T., 2009. Comparative assessment of the global fate and transport pathways of long-chain perfluorocarboxylic acids (PFCAs) and perfluorocarboxylates (PFCs) emitted from direct sources. Environ. Sci. Technol. 43 (15), 5830-5836.

Bao, J., Liu, W., Liu, L., Jin, Y., Dai, J., Ran, X., Zhang, Z., Tsuda, S., 2011. Perfluorinated compounds in the environment and the blood of residents living near fluorochemical plants in Fuxin, China. Environ. Sci. Technol. 45 (19), 8075-8080.

Blaine, A.C., Rich, C.D., Sedlacko, E.M., Hyland, K.C., Stushnoff, C., Dickenson, E.R., Higgins, C.P., 2014. Perfluoroalkyl acid uptake in lettuce (Lactuca sativa) and strawberry (Fragaria ananassa) irrigated with reclaimed water. Environ. Sci. Technol. 48 (24), 14361-14368.

Blum, A., Balan, S.A., Scheringer, M., Trier, X., Goldenman, G., Cousins, I.T., Diamond, M., Fletcher, T., Higgins, C., Lindeman, A.E., 2015. The Madrid statement on poly-and perfluoroalkyl substances (PFASs). Environ. Health Perspect. 123 (5), A107-A111.
Bossi, R., Strand, J., Sortkjaer, O., Larsen, M.M., 2008. Perfluoroalkyl compounds in Danish wastewater treatment plants and aquatic environments. Environ. Int. 34 (4), 443-450.

Cao, Y., Zhou, T, Liu, X, Zhag Y, Liu, Z, 2013. Predicted non-effect concentrations of perfluorooctanoic acid (PFOA) in the environment of China. Chin. Environ. Chem. 32, 1180-1187 (in Chinese with English abstract).

Dinglasan, M.J.A., Ye, Y., Edwards, E.A., Mabury, S.A., 2004. Fluorotelomer alcohol biodegradation yields poly-and perfluorinated acids. Environ. Sci. Technol. 38 (10), 2857-2864.

Domingo, J.L., 2012. Health risks of dietary exposure to perfluorinated compounds Environ. Int. 40, 187-195.

Dongyue Group Limited, 2012. 2012 Annual Report. http://www.dongyuechemcom/ UploadFiles/2013-3/News/20133201940820043.pdf (November 20, 2015) (in Chinese).

DWI (Drinking water inspectorate), U. D. W., 2009. Guidance on the water supply (water quality) regulations 20001 specific to PFOS (perfluorooctane sulphonate) and PFOA (perfluorooctanoic acid) concentrations in drinking water. Saatavissa: http://dwi.defra.gov.uk/stakeholders/informationletters/2009/10_2009annex. pdf (Viitattu 266 2014).

Eschauzier, C., Beerendonk, E., Scholte-Veenendaal, P., De Voogt, P., 2012. Impact of treatment processes on the removal of perfluoroalkyl acids from the drinking water production chain. Environ. Sci. Technol. 46 (3), 1708-1715.

Ferrey, M., Adair, C., Wilson, J., 2009. Sorption of PFOA and PFOS to aquifer sediment. Reprod. Toxicol. 27 (3), 416.

Gebbink, W.A., Glynn, A., Darnerud, P.O., Berger, U., 2015. Perfluoroalkyl acids and their precursors in Swedish food: the relative importance of direct and indirect dietary exposure. Environ. Pollut. 198, 108-115.

Gewurtz, S.B., Backus, S.M., De Silva, A.O., Ahrens, L., Armellin, A., Evans, M., Fraser S., Gledhill, M., Guerra, P., Harner, T., 2013. Perfluoroalkyl acids in the Canadian environment: multi-media assessment of current status and trends. Environ. Int. 59, 183-200.

Giesy, J.P., Kannan, K., 2001. Global distribution of perfluorooctane sulfonate in wildlife. Environ. Sci. Technol. 35 (7), 1339-1342.

Giesy, J.P., Kannan, K., 2002. Peer reviewed: perfluorochemical surfactants in the environment. Environ. Sci. Technol. 36 (7), 146A-152A.

Giesy, J.P., Naile, J.E., Khim, J.S., Jones, P.D., Newsted, J.L., 2010. Aquatic toxicology of perfluorinated chemicals. Rev. Environ. Contam. Toxicol. 202, 1-52.

Heydebreck, F., Tang, J., Xie, Z., Ebinghaus, R., 2015. Alternative and legacy perfluoroalky substances: differences between European and Chinese river/estuary systems. Environ. Sci. Technol. 49 (14), 8386-8395.

Higgins, C.P., Luthy, R.G., 2006. Sorption of perfluorinated surfactants on sediments. Environ. Sci. Technol. 40 (23), 7251-7256.

Jin, Y.H., Liu, W., Sato, I., Nakayama, S.F., Sasaki, K., Saito, N., Tsuda, S., 2009. PFOS and PFOA in environmental and tap water in China. Chemosphere 77 (5), 605-611. 
Kannan, K., Corsolini, S., Falandysz, J., Fillmann, G., Kumar, K.S., Loganathan, B.G., Mohd M.A., Olivero, J., Wouwe, N.V., Yang, J.H., 2004. Perfluorooctanesulfonate and related fluorochemicals in human blood from several countries. Environ. Sci. Technol. 38 (17), 4489-4495.

Kwok, K.Y., Taniyasu, S., Yeung, L.W., Murphy, M.B., Lam, P.K., Horii, Y., Kannan, K., Petrick G., Sinha, R.K., Yamashita, N., 2010. Flux of perfluorinated chemicals through wet deposition in Japan, the United States, and several other countries. Environ. Sci. Technol. 44 (18), 7043-7049.

Lescord, G.L., Kidd, K.A., De Silva, A.O., Williamson, M., Spencer, C., Wang, X., Muir, D.C., 2015. Perfluorinated and polyfluorinated compounds in lake food webs from the Canadian high Arctic. Environ. Sci. Technol. 49 (5), 2694-2702.

Li, L., Zhai, Z., Liu, J., Hu, J., 2015. Estimating industrial and domestic environmental releases of perfluorooctanoic acid and its salts in China from 2004 to 2012. Chemosphere 129, 100-109.

Lin, Y.-C., Lai, W.W.-P., Tung, H.-H., Lin, A.Y.-C., 2015. Occurrence of pharmaceuticals, hormones, and perfluorinated compounds in groundwater in Taiwan. Environ. Monit. Assess. 187 (5), 1-19.

Liu, S., Lu, Y., Xie, S., Wang, T., Jones, K.C., Sweetman, A.J., 2015. Exploring the fate, transport and risk of perfluorooctane sulfonate (PFOS) in a coastal region of China using a multimedia model. Environ. Int. 85, 15-26.

Mak, Y.L., Taniyasu, S., Yeung, L.W., Lu, G., Jin, L., Yang, Y., Lam, P.K., Kannan, K., Yamashita, N., 2009. Perfluorinated compounds in tap water from China and several other countries. Environ. Sci. Technol. 43 (13), 4824-4829.

Moody, C.A., Field, J.A., 1999. Determination of perfluorocarboxylates in groundwater impacted by fire-fighting activity. Environ. Sci. Technol. 33 (16), 2800-2806.

MWR (The Ministry of Water Resources of the People's Republic of China), 2011l. Water Resources Bulletin. http://www.mwr.gov.cn/zwzc/hygb/szygb/qgszygb/201212/ t20121217_335297.html (In Chinese).

MWR (The Ministry of Water Resources of the People's Republic of China), 20131. Water Resources Bulletin. http://www.mwr.gov.cn/zwzc/hygb/szygb/qgszygb/201411/ t20141120_582980.html (In Chinese).

MWR (The Ministry of Water Resources of the People's Republic of China), 2014l. Water Resources Bulletin. http://www.mwr.gov.cn/zwzc/hygb/szygb/qgszygb/201508/ t20150828_719423.html (In Chinese).

Persson, S., Rotander, A., Karrman, A., van Bavel, B., Magnusson, U., 2013. Perfluoroalkyl acids in subarctic wild male mink (Neovison vison) in relation to age, season and geographical area. Environ. Int. 59, 425-430.

Post, G., Stern, A., Murphy, E., 2011. Guidance for PFOA in drinking water at Pennsgrove water supply company. PDF). Department of Environmental Protection, Division of Science, Research and Technology, State of New Jersey, p. 2.

Prevedouros, K., Cousins, I.T., Buck, R.C., Korzeniowski, S.H., 2006. Sources, fate and transport of perfluorocarboxylates. Environ. Sci. Technol. 40 (1), 32-44.

Rumsby, P.C., McLaughlin, C.L., Hall, T., 2009. Perfluorooctane sulphonate and perfluorooctanoic acid in drinking and environmental waters. Philos. Trans. R. Soc London, Ser. A 367 (1904), 4119-4136.

Sharma, B.M., Bharat, G.K., Tayal, S., Larssen, T., Bečanová, J., Karásková, P., Whitehead P.G., Futter, M.N , Butterfield, D, Nizzetto, L, 2015. Perfluoroalkyl substances (PFAS) in river and ground/drinking water of the Ganges River basin: Emissions and implications for human exposure. Environ. Pollut.

Shi, Y., Vestergren, R., Xu, L., Song, X., Niu, X., Zhang, C., Cai, Y., 2015. Characterizing direct emissions of perfluoroalkyl substances from ongoing fluoropolymer production sources: a spatial trend study of Xiaoqing River, China. Environ. Pollut. 206, 104-112.

Taniyasu, S., Kannan, K., So, M.K., Gulkowska, A., Sinclair, E., Okazawa, T., Yamashita, N. 2005. Analysis of fluorotelomer alcohols, fluorotelomer acids, and short- and longchain perfluorinated acids in water and biota. J. Chromatogr. A 1093 (1-2), 89--97.

Taniyasu, S., Yamashita, N., Moon, H.B., Kwok, K.Y., Lam, P.K., Horii, Y., Petrick, G., Kannan, K. 2013a. Does wet precipitation represent local and regional atmospheric transportation by perfluorinated alkyl substances? Environ. Int. 55, 25-32.

Taniyasu, S., Yamashita, N., Yamazaki, E., Petrick, G., Kannan, K., 2013b. The environmental photolysis of perfluorooctanesulfonate, perfluorooctanoate, and related fluorochemicals. Chemosphere 90 (5), 1686-1692.

UNEP, 2009. The conference of the parties 4 of the Stockholm Convention (COP-4) in Geneva placed perfluorooctane sulfonate and perfluorooctane sulfonyl fluoride
(PFOS and PFOSF) in Annex B. http://chm.pops.int/Convention/Pressrelease/ COP4Geneva9May2009/tabid/542/language/en-US/Default.aspx2009.

USEPA, 2013. The 2010/2015 PFOA Stewardship Program. http://www.epa.gov/oppt/ pfoa/pubs/stewardship/ (accessed 11.19.15).

USEPA, 2014. Emerging contaminants - perfluorooctane sulfonate (PFOS) and perfluorooctanoic acid (PFOA). http://www2.epa.gov/sites/production/files/ 2014-04/documents/factsheet_contaminant_pfos_pfoa_march2014.pdf.

Wang $\mathrm{Y}, \mathrm{Fu}, \mathrm{J}$, Wang $\mathrm{T}$, Liang $\mathrm{Y}$, Pan, Y, Cai, Y, Jiang, G, 2010. Distribution of perfluorooctane sulfonate and other perfluorochemicals in the ambient environment around a manufacturing facility in China. Environ. Sci. Technol. 44 (21), 8062-8067.

Wang, T., Khim, J.S., Chen, C., Naile, J.E., Lu, Y., Kannan, K., Park, J., Luo, W., Jiao, W., Hu, W., Giesy, J.P., 2012. Perfluorinated compounds in surface waters from Northern China: comparison to level of industrialization. Environ. Int. 42, 37-46.

Wang, P., Wang, T., Giesy, J.P., Lu, Y., 2013. Perfluorinated compounds in soils from Liaodong Bay with concentrated fluorine industry parks in China. Chemosphere. 91 (6), 751-757.

Wang, Z., Cousins, I.T., Scheringer, M., Buck, R.C., Hungerbuhler, K., 2014a. Global emission inventories for C4-C14 perfluoroalkyl carboxylic acid (PFCA) homologues from 1951 to 2030, Part I: production and emissions from quantifiable sources. Environ. Int. 70, 62-75.

Wang, P., Lu, Y., Wang, T., Fu, Y., Zhu, Z., Liu, S., Xie, S., Xiao, Y., Giesy, J.P., 2014b. Occurrence and transport of 17 perfluoroalkyl acids in 12 coastal rivers in south Bohai coastal region of China with concentrated fluoropolymer facilities. Environ. Pollut. 190, 115-122.

Wang, Z., Cousins, I.T., Scheringer, M., Buck, R.C., Hungerbuhler, K., 2014c. Global emission inventories for C4-C14 perfluoroalkyl carboxylic acid (PFCA) homologues from 1951 to 2030, part II: the remaining pieces of the puzzle. Environ. Int. 69, 166-176.

Wang, Z., Cousins, I.T., Scheringer, M., Hungerbuehler, K., 2015. Hazard assessment of fluorinated alternatives to long-chain perfluoroalkyl acids (PFAAs) and their precursors: status quo, ongoing challenges and possible solutions. Environ. Int. 75, 172-179.

Wang, P., Lu, Y., Wang, T., Meng, J., Li, Q., Zhu, Z., Sun, Y., Wang, R., Giesy, J.P., 2016. Shifts in production of perfluoroalkyl acids affect emissions and concentrations in the environment of the Xiaoqing River Basin, China. J. Hazard. Mater. 307, 55-63.

Wen, B., Li, L., Zhang, H., Ma, Y., Shan, X.Q., Zhang, S., 2014. Field study on the uptake and translocation of perfluoroalkyl acids (PFAAs) by wheat (Triticum aestivum L.) grown in biosolids-amended soils. Environ. Pollut. 184, 547-554.

Wilhelm, M., Bergmann, S., Dieter, H.H., 2010. Occurrence of perfluorinated compounds (PFCs) in drinking water of North Rhine-Westphalia, Germany and new approach to assess drinking water contamination by shorter-chained C4-C7 PFCs. Int. J. Hyg. Environ. Health 213 (3), 224-232.

Xiao, F., Halbach, T.R., Simcik, M.F., Gulliver, J.S., 2012a. Input characterization of perfluoroalkyl substances in wastewater treatment plants: source discrimination by exploratory data analysis. Water Res. 46 (9), 3101-3109.

Xiao, F., Simcik, M.F., Gulliver, J.S., 2012b. Perfluoroalkyl acids in urban stormwater runoff: influence of land use. Water Res. 46 (20), 6601-6608.

Xiao, F., Simcik, M.F., Gulliver, J.S., 2013. Mechanisms for removal of perfluorooctane sulfonate (PFOS) and perfluorooctanoate (PFOA) from drinking water by conventional and enhanced coagulation. Water Res. 47 (1), 49-56.

Xiao, F., Simcik, M.F., Halbach, T.R., Gulliver, J.S., 2015. Perfluorooctane sulfonate (PFOS) and perfluorooctanoate (PFOA) in soils and groundwater of a US metropolitan area: migration and implications for human exposure. Water Res. 72, 64-74.

Xie, S., Lu, Y., Wang, T., Liu, S., Jones, K., Sweetman, A., 2013a. Estimation of PFOS emission from domestic sources in the eastern coastal region of China. Environ. Int. 59, 336-343.

Xie, S., Wang, T., Liu, S., Jones, K.C., Sweetman, A.J., Lu, Y., 2013b. Industrial source identification and emission estimation of perfluorooctane sulfonate in China. Environ. Int. 52, 1-8.

Yamashita, N., Taniyasu, S., Petrick, G., Wei, S., Gamo, T., Lam, P.K., Kannan, K., 2008. Perfluorinated acids as novel chemical tracers of global circulation of ocean waters. Chemosphere 70 (7), 1247-1255.

Yeung, L.W., De Silva, A.O., Loi, E.I., Marvin, C.H., Taniyasu, S., Yamashita, N., Mabury, S.A., Muir, D.C., Lam, P.K., 2013. Perfluoroalkyl substances and extractable organic fluorine in surface sediments and cores from Lake Ontario. Environ. Int. 59, 389-397. 